\title{
Satisfaction with travel and residential self-selection: How do preferences moderate the impact of the Hiawatha Light Rail Transit line?
}

\author{
Xinyu "Jason" Cao ${ }^{a}$ \\ University of Minnesota, Twin Cities
}

\author{
Dick F. Ettema ${ }^{\mathrm{b}}$ \\ Utrecht University
}

\begin{abstract}
Policies in urban and transportation planning increasingly aim at improving residents' wellbeing. Satisfaction with travel (SWT) is a relevant component of well-being. Insight into the effect of the built environment on SWT is limited and therefore the focus of this paper. To assess this effect, a crucial issue is to what extent a relationship between the built environment and SWT is due to residential self-selection. To explore this question, a survey was held in corridors of the Twin Cities, which differed in terms of accessibility and transit options. Respondents reported their SWT, travel preferences and reasons for location choices, among other things. Using a fixed-effect model of SWT, we found that self-selection plays a significant role in explaining SWT, but that built environment characteristics also have an independent effect on SWT. Taken together this suggests that policies to build high-quality transit have a positive effect on SWT, in general, and particularly for those with a transit preference.
\end{abstract}

\section{Introduction}

Creating livable communities has become a centerpiece of planning practice at federal, regional and local governments. Many guidelines have been proposed and implemented to improve individuals' wellbeing. For example, the Metropolitan Council in the Minneapolis-St. Paul metropolitan area (Twin Cities) uses its "Guide for Transit-Oriented Development" as a reference for its Livable Communities Act-Transit-Oriented Development Grant program. The Obama administration established an Interagency Partnership for Sustainable Communities in 2009 and adopted six livability principles (www. sustainablecommunities.gov/). Among the guidelines, transportation is a critical component in facilitating livable communities. This highlights the importance of improving transportation infrastructure and services and enhancing individuals' satisfaction with travel (SWT). However, there is limited evidence regarding the impacts of improvements in infrastructure and the surrounding environment on SWT.

A number of studies have explored SWT and its correlates (Abou-Zeid et al. 2012; Olsson et al. 2013). Many focus on the SWT of specific trips and the impact of trip characteristics on the SWT. Resulting from aggregated travel experiences, people will develop an overall assessment of the travel that forms part of their daily lives, which influences their well-being. This overall SWT may be influenced by characteristics of the transportation system and accessibility to destinations from the home location facilitated by the transportation system. Their influence on overall SWT has, however, received limited attention to date. Particularly, while rail transit has been advocated as a significant improvement of the transit system and a driver for ridership growth, the empirical evidence regarding its impact on SWT is scarce. Residential self-selection may further complicate the influences of rail transit and its surrounding built environment on SWT. In this context, residential self-selection implies that those with a preference for (rail) transit are more likely to benefit from the presence of rail transit and thus more often choose to

acao@umn.edu

bD.F.Ettema@uu.nl

Copyright 2014 Xinyu "Jason" Cao and Dick F. Ettema.

Licensed under the Creative Commons Attribution - NonCommercial License 3.0. 
reside in areas where it is offered, so that the impact of rail transit on SWT is confounded by residents' preferences.

Using data gathered for the Hiawatha Light Rail Transit (LRT) in the Twin Cities, this study examines the influences of LRT, built environment elements, and residential self-selection on satisfaction with travel. It aims to answer the following questions: (1) Does self-selection moderate the relationships between the built environment and SWT? (2) What elements of the built environment are associated with SWT after controlling for self-selection? (3) What is the relative importance of built environment characteristics and self-selection in explaining SWT? And (4) what role does the LRT play in promoting SWT? This paper is organized as follows: In the next section we review the literature pertaining to the determinants of SWT and the confounding effect of residential self-selection. Section 3 describes the data and variables. Section 4 presents our hypotheses and model results, and the last section summarizes the key findings.

\section{Literature Review}

\subsection{Subjective well-being and satisfaction with travel}

The past decades have witnessed an increased interest in individuals' well-being and how it is influenced by life circumstances and policies. In investigating well-being, different schools are distinguished. Those applying a "hedonic" perspective typically focus on direct indicators of well-being and investigate correlations between life circumstances and these indicators. Indicators of well-being include cognitive items, expressing an overall assessment of how good one's life is, and affective items, expressing to what extent positive or negative emotions are experienced (Diener et al. 1999). In contrast, the "eudaimonic" perspective of well-being focuses on the processes underlying well-being (Ryff and Singer 2008; Deci and Ryan 2000). In the eudaimonic tradition, it has been found that issues such as autonomy, achievement, environmental mastery and social interactions are important factors defining well-being. To some extent (Huta and Ryan 2010) one can argue that the hedonic indicators of well-being signal to what extent eudaimonic goals are met, although hedonic enjoyment also is a goal that people pursue for its own sake. Overall, the hedonic approach is mainstream in well-being research and the combined use of cognitive and affective evaluations to measure well-being is usually termed subjective well-being (SWB).

Travel behavior is related to SWB in two principal ways (Ettema et al. 2010). First, travel allows one to participate in activities, which may contribute to one's SWB. In this respect, it has been shown (see Bergstad et al. 2011) that participation in activities has an impact on SWB, and that higher satisfaction with activities leads to a higher overall SWB. Various studies in the social exclusion area (e.g., Delbosc and Currie 2011; Stanley et al. 2011) show that lack of transportation options and associated social exclusion lead to considerably lower levels of well-being. Second, the activity of traveling in itself may be experienced as more or less pleasant. Whereas travel has traditionally been regarded as a disutility and unproductive time, Mokhtarian and Salomon (2001) emphasized that travel time may be experienced as a positive activity, due to the option to undertake activities during travel (Ettema et al. 2012), for example, as a way to relax and unwind (Jain and Lyons 2008) or because travel in itself is enjoyed (Middleton 2009). A recent study in Sweden (Olsson et al. 2013) revealed that commuters on average experience positive well-being during trips, with trips by slow modes (walking and cycling) giving higher well-being and trips made by public transport yielding lower well-being, compared to trips made by car. However, travel may occasionally be experienced as negative due to stress experienced while driving a car (Hennessy and Wiesenthal 1999), for example, or negative incidents in public transport (Friman and Gärling 2001).

In recognition of the impact of travel on well-being, Bergstad et al. (2011) developed a SWT 
scale that taps the cognitive evaluation of travel. It can be applied on different levels of specificity. For instance, although Ettema et al. (2012) applied the scale to specific trips made on a particular day, Olsson et al. (2013) applied the scale to measure satisfaction with the average commute trip. In addition, the SWT scale can be applied to measure one's overall satisfaction with travel for various purposes as determined by the quality of the transportation system, accessibility of relevant destinations and local opportunities for walking and cycling.

For specific trips, satisfaction with travel has been found to be influenced by travel mode, travel duration, travel company, trip purpose, activities during travel, occurrence of delays/congestion, seating probability, and service supply (Friman and Felleson 2009). Individual preferences also play a role. Many studies (e.g., Bamberg and Schmidt 2003) have shown that if people hold an a priori attitude toward certain travel modes, it is likely to influence the effect of using them on their well-being. For example, Abou-Zeid et al. (2012) suggests that car commuters' satisfaction of their trip depends on their attitudes toward punctuality and flexibility of the car.

A key issue in the context of this paper is how a residential setting influences SWT. Because the built environment influences travel options, it is plausible to expect that the built environment at least indirectly affects SWT. Further, the built environment is the domain where travel occurs, so its quality may impact individuals' experience with travel. If so, planners can design and implement land-use and transportation policies to improve neighborhood characteristics and hence, enhance SWT. However, the literature provides only limited clues as to how this relationship materializes. Stutzer and Frey (2008) find that a long commute has a negative impact on commuters' well-being, suggesting that the spatial distribution of jobs and residences affects SWT. Delbosc and Currie (2011) find that perceived transport disadvantage leads to lower well-being, and the former is related to the availability of transit systems among other things. Olsson et al. (2013) note that slow mode use leads to higher SWT, suggesting that SWT should be higher in areas with better walkability and cycling conditions; however, travel satisfaction was not assessed in geographical terms in this study. Hence, the relationship between the built environment and SWT has been largely ignored.

\subsection{Residential self-selection and travel satisfaction}

In the context of travel behavior, residential self-selection means that people choose their residential location based on their travel needs and preferences (Mokhtarian and Cao 2008). Self-selection generally results from socio-demographics and predispositions toward travel and residential choices. For example, individuals who prefer transit may selectively live in a transit-friendly neighborhood and use transit frequently. In this case, although the neighborhood is associated with transit use, it may not be not the neighborhood per se but transit preference that determines travel behavior. If a self-selection effect exists, but is not controlled for, it is likely to misestimate the impact of the built environment on travel behavior (Chatman 2009; Bhat and Guo 2007).

During the past two decades, dozens of studies have addressed the issue of residential self-selection in the relationship between the built environment and travel behavior. The studies have employed various modeling techniques, including statistical control (Frank et al. 2007; Næss 2009), instrumental variables (Boarnet and Sarmiento 1998; Khattak and Rodriguez 2005), sample-selection model (Bhat and Eluru 2009; Zhou and Kockelman 2008), propensity score matching (Cao and Fan 2012), joint modeling (Scheiner 2010; Pinjari et al. 2011), and longitudinal design (Krizek 2003; Brown and Werner 2007). Among the approaches, statistical control is the most commonly used method in the literature.

A recent review of 38 empirical studies concludes that residential self-selection contributes to the association between the built environment and travel behavior and that virtually all studies find an independent impact of the built environment on travel beyond residential self-selection (Cao, Mokhtarian, 
and Handy 2009). Hence, the observed impact of the built environment (without controlling for selfselection) on travel consists of two components: built environment effect and self-selection effect. Since practitioners are interested in understanding whether the observed built environment impact on travel diminishes once self-selection effect is controlled for, researchers call for an evaluation of the relative contributions of the built environment and self-selection on travel behavior (Mokhtarian and Cao 2008). Limited evidence suggests that the impact of built environment on travel exceeds the self-selection effect (Cao and Fan 2012).

Self-selection issues in travel behavior studies carry important implications for SWT research. Although few studies have focused on the association between the built environment and SWT, an observed association, if any, may result from residential self-selection. For instance, if a certain mode of transport is associated with SWT as Olsson et al. (2013) notes, individuals who put a high weight on SWT are likely to seek a neighborhood conducive to using this mode. Stanbridge and Lyons (2006) provides evidence that travel considerations indeed play a role for some in selecting a residential location, and that the extent to which travel considerations play a role varies greatly among individuals. As a logical corollary of this mechanism, the effect of improvements in the transportation system or the built environment on SWT will depend on individuals travel preferences, the mismatch between travel preferences and travel conditions, and the extent to which travel-related residential self-selection plays a role. Thus, many questions regarding self-selection in the travel behavior research will apply to the SWT research when planners look to use land-use and transportation policies to affect well-being. To contribute to this field of research, this study focuses on the four questions presented in section 1. Using fixed effect models, we investigate how residents' satisfaction with their general travel conditions depends on socio-demographics, characteristics of the neighborhood and the transport system and indicators of selfselection. Comparing the relative impacts of these types of factors will shed light on the extent to which SWT is the outcome of residential self-selection processes

\section{Data and variables}

The data came from a self-administered 10-page survey mailed in May 2011 to households in five corridors in the Twin Cities. The target corridor is Hiawatha Avenue, where the LRT is located (http://metrotransit.org/light-rail). The 12-mile line has 19 stations and runs north to south between downtown Minneapolis and the Mall of America in Bloomington, Minn., through the Minneapolis-St. Paul International Airport (MSP). There are five stations located in the northernmost downtown Minneapolis area and six stations located at the southernmost part of the line, starting at the MSP and ending at the Mall of America. The station areas at either end of the line are dominated by commercial developments or institutional land uses, while the station areas in the middle of the line are dominated by industrial land uses and residential properties. The Hiawatha corridor used in this study consists of the middle section of the line, in particular, the area within one-half mile of the Hiawatha LRT from Lake Street to 50th Street.

We chose two sets of control corridors (Figure 1). Because a random experiment is not feasible, we employed a case-control observational design. First, we attempted to find urban corridors that resemble the Hiawatha corridor in terms of location context, built environment elements, transit access, and socio-demographics. With the help of local planners, we chose the areas along Nicollet Avenue and Bloomington Avenue in South Minneapolis as our urban control corridors. The two corridors are parallel to the Hiawatha line. Then we selected Coon Rapids and Burnsville as our suburban control corridors. Coon Rapids is about 14 miles directly north of downtown Minneapolis and Burnsville is 17 miles directly south of downtown. The suburban corridors have socio-demographics similar to the Hiawatha corridor but were mainly developed in the 1970s. The suburban corridors have limited access 


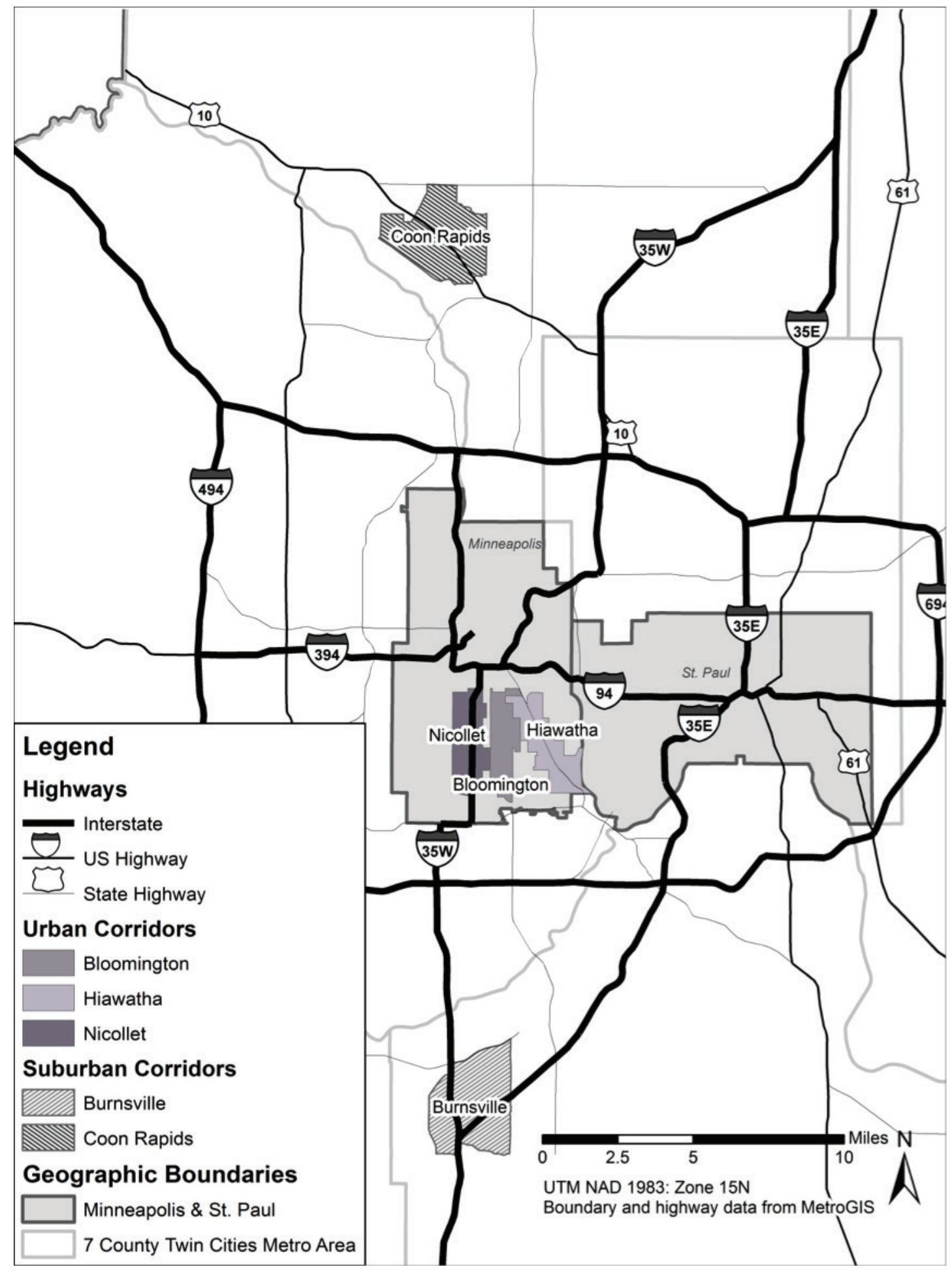

Figure 1: Hiawatha corridor and control corridors.

to transit, compared to urban corridors, and their street networks are mainly curvilinear (Figure 2).

The survey was pretested by students and staff members from the Humphrey School of Public Affairs and by neighbors and friends of the investigators. Survey content was revised based on the feedback from the pre-testers. The survey and two reminder postcards (sent one and two weeks later) were 


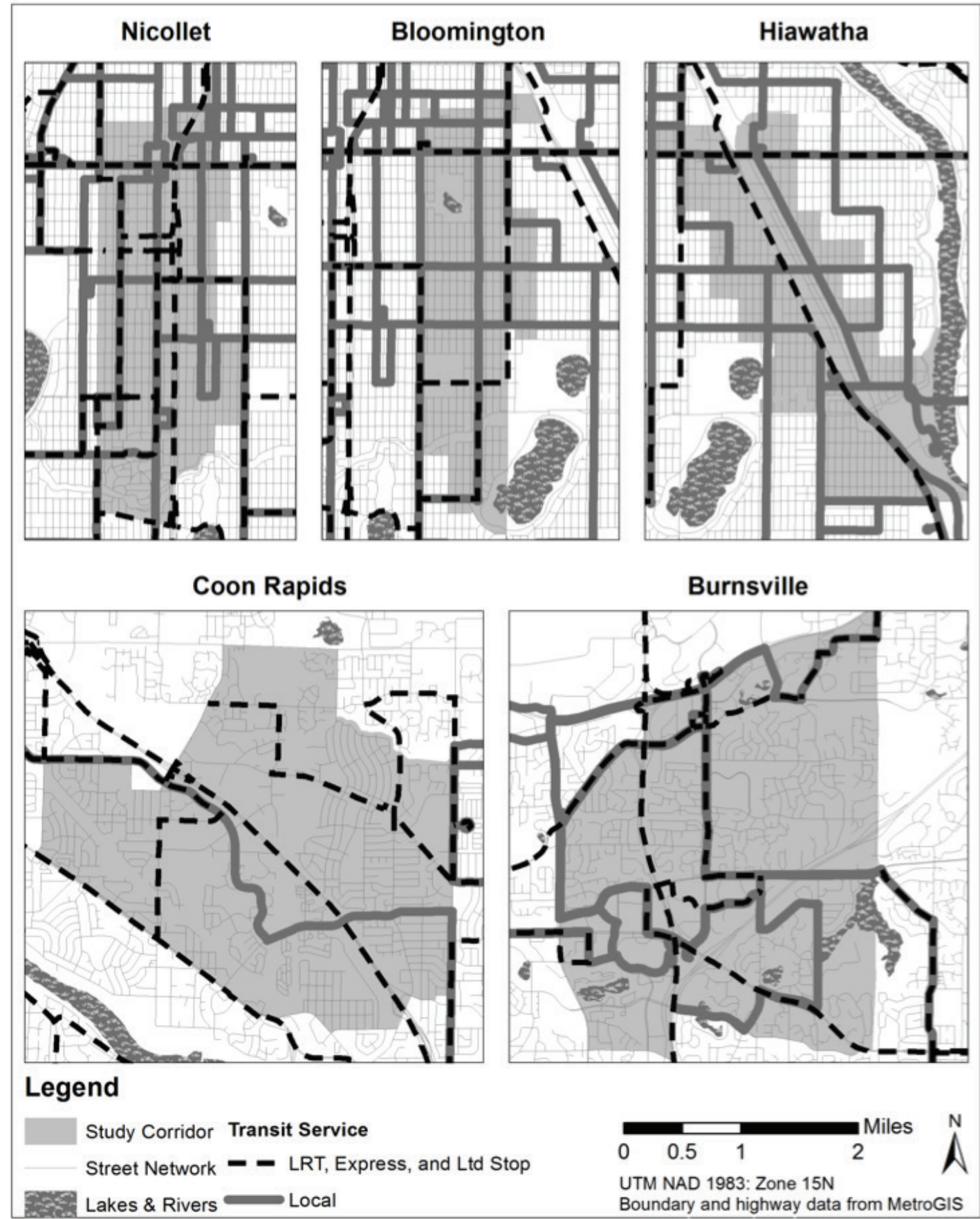

Figure 2: Map of corridors. Note: LRT is available only in the Hiawatha corridor.

mailed in May 2011. The chance to win $10 \$ 50$ gift cards was provided as an incentive for completing the survey. We purchased 2000 random addresses from the Hiawatha corridor and 1000 addresses from each of the Nicollet, Bloomington, Coon Rapids, and Burnsville corridors from AccuData Integrated Marketing, a commercial data provider (www.accudata.com). The original database consisted of 6017 addresses, but only 5884 were valid. The number of responses totaled 1303 , equivalent to a 22.2 percent response rate based on the valid addresses only. This is considered quite good for a survey of this length, since the response rate for a survey administered to the general population is typically between 
Table 1: Sample characteristics vs. 2010 Census.

\begin{tabular}{|l|r|c|r|r|r|r|r|r|r|c|c|}
\hline \multirow{2}{*}{} & \multicolumn{2}{|c|}{ Hiawatha } & \multicolumn{2}{c|}{ Nicollet } & \multicolumn{2}{c|}{ Bloomington } & \multicolumn{2}{c|}{ Coon Rapids } & \multicolumn{2}{c|}{ Burnsville } \\
\cline { 2 - 13 } & Census & Sample & Census & Sample & Census & Sample & Census & Sample & Census & Sample \\
\hline Number of people & 24,166 & 508 & 36,808 & 197 & 27,055 & 241 & 24,866 & 175 & 27,975 & 182 \\
\hline Percent of female & $50 \%$ & $52 \%$ & $49 \%$ & $49 \%$ & $50 \%$ & $51 \%$ & $51 \%$ & $49 \%$ & $52 \%$ & $49 \%$ \\
\hline Mean household size & 2.27 & 2.15 & 2.50 & 2.21 & 2.65 & 2.26 & 2.53 & 2.42 & 2.31 & 2.24 \\
\hline Percent with kids & $26 \%$ & $23 \%$ & $43 \%$ & $22 \%$ & $35 \%$ & $24 \%$ & $32 \%$ & $29 \%$ & $35 \%$ & $22 \%$ \\
\hline Percent of owner & $68 \%$ & $83 \%$ & $49 \%$ & $82 \%$ & $62 \%$ & $84 \%$ & $77 \%$ & $86 \%$ & $58 \%$ & $84 \%$ \\
\hline
\end{tabular}

10 percent and 40 percent (Sommer and Sommer 1997). Table 1 compares sample characteristics with the 2010 Census. Overall, homeowners are overrepresented in the sample, although the percentages of owners across different corridors were similar. Respondents tend to live in a smaller household than the population at large, and households with children are underrepresented. However, since the focus of our study is on explaining the relationships of other variables to SWT rather than on describing SWT per se, these differences are not expected to materially affect the results (Babbie 2007).

The variables include six categories: satisfaction with travel, transit use, neighborhood characteristics, residential preferences, travel preferences, and socio-demographics. SWT is measured using the Satisfaction with Travel Scale (SWTS) developed by Bergstad et al. (2011). The SWTS includes five statements: "I am completely satisfied with my daily travel," "My daily travel makes me feel good," "My travel facilitates my daily life," "I do not want to change anything regarding my daily travel," and "When I think of my daily travel, the positive aspects outweigh the negative." Respondents rated these statements on a seven-point scale ranging from "strongly disagree" (1) to "strongly agree" (7). The statements "measure satisfaction with daily travel without focusing on any particular travel mode" (p. 6). The Cronbach's $\alpha$ for the statements is 0.85 . An exploratory factor analysis reduced these statements into one SWT dimension. Specifically, we applied principle axis factoring in SPSS 21 and used eigenvalue $>1$ as the selection criterion. The factor loadings of the statements are $0.91,0.82,0.45,0.78$, and 0.70 , respectively. The variance explained by the factor is about 64 percent.

Transit use includes commute frequency and non-work travel frequency. In the survey, respondents were asked to indicate the number of days they used bus/rail to commute in a typical month with good weather, based on a six-point ordinal scale ranging from "never," "less than once per month," "one to three times per month," "Once per week," "two to three days per week," to "four to five days per week." They were recoded as approximately $0,0.5,2,4.3,10.75$, and 19.35 times per month, respectively. Respondents were also asked to answer the following question: "In a typical month with good weather, how often do you take public transit from your home to each of the following places for purposes other than work/school?" The destinations/purposes include a religious or civic building (e.g., library), a service provider (e.g., bank, barber), a store or place to shop, a restaurant or coffee place, a place for entertainment/recreation, a place to exercise (e.g., gym or park), and to pick up or drop off a passenger. The choice set included "never," "less than once per month," "once or twice per month," "about once every two weeks," "about once per week," and "two or more times per week." Similarly, they were recoded as $0,0.5,1.5,2.15,4.3$, and 12.9 times per month, respectively. Non-work transit frequency is the summation of frequencies for the seven purposes.

Respondents were also asked to indicate how true 30 characteristics are for their neighborhood on a four-point scale from "not at all true" (1) to "entirely true" (4). The 30 statements cover attributes associated with living units, land use and transportation systems, safety, social environment, and so on. Also the importance of these items to respondents when/if they were looking for a new place to live were measured on a four-point scale from "not at all important" (1) to "extremely important" (4). The com- 
parison of an individual's perceived neighborhood characteristics for his or her current residence and his or her neighborhood characteristic preferences indicates how well the current neighborhood meets the individual's preferences. In this study, we focus on 10 attributes pertaining to land use and transportation systems. A factor analysis reduces them into three factors: transit option, accessibility, and physical

Table 2: Pattern matrix for perceived neighborhood characteristics and residential preferences.

\begin{tabular}{|l|c|c|c|}
\hline Statements & Physical activity option & Access & Transit option \\
\hline Good bicycle routes beyond the neighborhood & 0.745 & & \\
Sidewalks throughout the neighborhood & 0.548 & & \\
Parks and open spaces nearby & 0.446 & \\
Easy access to a regional shopping mall & & 0.744 & \\
Religious or civic buildings (i.e., library) nearby & & 0.513 & \\
Shopping areas within walking distance & & 0.343 & \\
Easy access to downtown & & $<0.300$ & \\
Close to where I work & & & \\
Good public transit service (bus or rail) & & & 0.941 \\
Easy access to transit stop/station & & & 0.927 \\
\hline
\end{tabular}

Note: The method was principal axis factoring with Oblimin with Kaiser normalization. The variance explained is 60 percent. Loadings smaller than 0.300 were suppressed. To make neighborhood characteristics and residential preferences comparable, we conducted factor analysis for them jointly so the two sets of factors share the same pattern matrix.

activity option (Table 2).

Following the survey, we constructed 15 objective built environment measures around each respondent's home address using ArcGIS. Some variables measure the distance from each respondent's home address to the nearest feature, such as transit stops. We also measure characteristics around each respondent's home, using a one-half-mile network distance buffer. The variables include measures related to density (such as population density and housing density), diversity (such as entropy indices of land use mix and business mix), design (such as number of four-/five-way intersections and cul-de-sacs), distance to activities (such as gym and shops) and access to transit (distance to the closest station and stop density).

To measure travel preferences, the survey asked respondents whether they agreed or disagreed with 21 statements on a five-point scale from "strongly disagree" (1) to "strongly agree" (5). Factor analysis was then used to extract the fundamental dimensions spanned by the items, since some of the items are highly correlated. As shown in Table 3, seven underlying dimensions were identified: pro-drive, prowalk, pro-bike, pro-transit, safety of car, status of car and pro-travel.

The survey also contains 12 socio-demographics, which may contribute to explaining respondents' SWT. They consist of gender, age, education, employment status, mobility constraints, income, auto ownership, bike ownership, household size and number of children.

\section{$4 \quad$ Modeling and results}

Table 4 illustrates SWT as well as travel preferences and perceived neighborhood characteristics of different corridors. First, a t-test indicates that residents in the Hiawatha corridor tend to have a higher level of SWT than those in the other four corridors as a whole. A further post-hoc Bonferroni test of ANOVA shows that Hiawatha residents tend to be more satisfied with travel than residents in the urban control corridors, and there is no significant difference between residents in the Hiawatha and suburban 
Table 3: Pattern matrix for travel attitudes.

\begin{tabular}{|c|c|c|c|c|c|c|c|}
\hline & Safety of car & Status of car & Pro-travel & Pro-drive & Pro-transit & Pro-bike & Pro-walk \\
\hline Traveling by car is safer overall than walking. & 0.748 & & & & & & \\
\hline Traveling by car is safer overall than taking transit. & 0.582 & & & & & & \\
\hline Traveling by car is safer overall than riding a bicycle. & 0.335 & & & & & -0.308 & \\
\hline It does not matter to me which type of car I drive. & & -0.642 & & & & & \\
\hline To me, the car is nothing more than a convenient way to get around. & & -0.601 & & & & & \\
\hline To me, the car is a status symbol. & & 0.324 & & 0.341 & & & \\
\hline Travel time is generally wasted time. & & & -0.615 & & & & \\
\hline The only good thing about traveling is arriving at your destination. & & & -0.544 & & & & \\
\hline Getting there is half the fun. & & & 0.446 & 0.384 & & & \\
\hline I like to drive just for fun. & & & & 0.692 & & & \\
\hline I like driving. & & & & 0.665 & & & \\
\hline I feel free and independent if I drive. & & & & 0.491 & & & \\
\hline I like taking transit. & & & & & 0.754 & & \\
\hline Public transit can sometimes be easier for me than driving. & & & & & 0.737 & & \\
\hline I prefer to take transit rather than drive whenever possible. & & & & & 0.711 & & \\
\hline I prefer to bike rather than drive whenever possible. & & & & & & 0.846 & \\
\hline Biking can sometimes be easier for me than driving. & & & & & & 0.829 & \\
\hline I like riding a bike. & & & & & & 0.783 & \\
\hline I prefer to walk rather than drive whenever possible. & & & & & & & 0.734 \\
\hline I like walking. & & & & & & & 0.650 \\
\hline Walking can sometimes be easier for me than driving. & & & & & & & 0.546 \\
\hline
\end{tabular}

Note: The method was principal axis factoring with Oblimin with Kaiser normalization. The variance explained is 69 percent. Loadings smaller than 0.300 were suppressed.

Table 4: Satisfaction with travel by corridor.

\begin{tabular}{|l|c|c|c|c|c|c|c|c|c|c|c|c|}
\hline Corridor & N & SWT & $\begin{array}{c}\text { Pro- } \\
\text { transit }\end{array}$ & $\begin{array}{c}\text { Pro- } \\
\text { drive }\end{array}$ & $\begin{array}{c}\text { Pro- } \\
\text { bike }\end{array}$ & $\begin{array}{c}\text { Safety } \\
\text { of car }\end{array}$ & $\begin{array}{c}\text { Pro- } \\
\text { walk }\end{array}$ & $\begin{array}{c}\text { Status } \\
\text { of car }\end{array}$ & $\begin{array}{c}\text { Pro- } \\
\text { travel }\end{array}$ & $\begin{array}{c}\text { Perceived } \\
\text { transit }\end{array}$ & $\begin{array}{c}\text { Perceived } \\
\text { PA option }\end{array}$ & $\begin{array}{c}\text { Perceived } \\
\text { access }\end{array}$ \\
\hline Hiawatha & 498 & 0.102 & 0.385 & -0.103 & 0.156 & -0.114 & 0.146 & -0.072 & -0.056 & 0.598 & 0.641 & 0.423 \\
\hline Burnsville & 179 & 0.097 & -0.470 & 0.188 & -0.564 & 0.188 & -0.445 & 0.067 & 0.173 & -0.436 & -0.959 & 0.706 \\
\hline Coon Rapids & 172 & -0.133 & -0.660 & 0.293 & -0.381 & 0.283 & -0.500 & 0.086 & -0.107 & -0.611 & -0.727 & -0.035 \\
\hline Bloomington & 239 & -0.125 & -0.036 & -0.035 & 0.261 & -0.120 & 0.132 & 0.068 & 0.084 & 0.291 & 0.606 & -0.049 \\
\hline Nicollet & 194 & -0.080 & 0.076 & -0.125 & 0.135 & 0.017 & 0.317 & -0.038 & -0.026 & 0.377 & 0.568 & 0.158 \\
\hline
\end{tabular}

control corridors.

\subsection{Modeling approach}

Fixed-effect linear regression is employed to explore the correlates of SWT. Our data are collected using a clustered sampling approach. Residents in the same corridor may share some unobserved attributes. Ignoring the clustering effect may lead to biased estimates of standard errors and accordingly may make statistical inferences invalid, leading to false conclusions that non-existing relationships are significant or that existing relationships are insignificant (Snijders and Bosker 1999). Multilevel models can be used to correct for the clustering effect. Because we assume a constant and independent impact of neighborhood on SWT, we follow Snijders and Bosker's suggestion and choose to employ a fixed effect model 
(FEM). Specifically, we include dummy variables indicating different corridors in the models, with the Hiawatha corridor being the reference category.

As discussed in Section 2.1, the built environment has the potential to influence SWT. Ignoring preference-induced self-selection, SWT can be expressed as a function of neighborhood characteristics (NC) and other observed variables such as socio-demographics (X):

$$
S W T=f_{l}(N C, X)+\varepsilon .
$$

If travel and residential preferences (TRP) are unobserved, their influence will be contained in the error term $\varepsilon$. Because people self-select their residential location, NC is also a function of TRP. That is,

$S W T=f_{l}(N C(T R P), X)+\varepsilon(T R P)$

The correlation between NC and $\varepsilon$ through TRP leads to endogeneity bias. The statistical control approach explicitly accounts for the influence of TRP in analyzing SWT by measuring them and including them in the SWT equation:

$$
\mathrm{SWT}=f_{2}(N C, T R P, X)+\xi
$$

This equation removes TRP from the $\varepsilon$ of Equation (2), and hence $\mathrm{NC}$ is presumably uncorrelated with $\xi$. If the inclusion of TRP makes NC insignificant, a natural conclusion is that the influence of NC on SWT is entirely due to self-selection. Otherwise NC has its own influence on SWT (Mokhtarian and Cao 2008).

In addition, residents' travel behavior (TB) may influence SWT directly. Assuming that some travel modes are inherently more attractive to people than others (Olsson et al. 2013), the relative frequency of trips made by each mode may influence SWT. The interpretation of travel-mode use may, however, differ between spatial contexts. Using transit frequently in a car-oriented environment such as Burnsville or Coon Rapids may be indicative of "forced" transit use due to lack of a car. Using transit frequently in a place with good transit options, such as Hiawatha, likely indicates a deliberate choice of using transit in an environment conducive to this type of travel.

Given the presence of corridor dummies relative to the LRT in FEM, the prediction equation for SWT without controlling for preference-induced self-selection can be expressed as

$$
S W T=f(L R T, N C, T B, X)
$$

By considering TRP and its their interaction terms with the built environment, the equation becomes

$$
S W T=f(L R T, N C, T B, X, T R P,(L R T \times T R P),(N C \times T R P))
$$

Because TRP are potential indicators of self-selection, the interactions of TRP with built environment variables are indicative of self-selection effects. For instance, it allows us to answer questions such as: Do people who have moved for transit reasons profit more from access to transit than others $(\mathrm{NC} \times \mathrm{TRP})$ ? Do people with a positive attitude toward transit profit from living near rail transit $(\mathrm{LRT} \times \mathrm{TRP})$ ? 


\subsection{Results}

According to the statistical control approach, we developed two models: Model 1 includes corridor dummies, socio-demographics, transit use, and neighborhood characteristics, and Model 2 further incorporates travel and residential preferences and their interactions with neighborhood characteristics (Table 5). Although we tested all of the 40 independent variables described in Section 3, we retained those significant at the 0.05 level (except for corridor dummies because of FEM) to produce parsimonious models in Table 5. In Model 2, 12 variables (including interaction terms) are significant and more

Table 5: Linear regression for satisfaction with travel.

\begin{tabular}{|c|c|c|c|c|}
\hline \multirow[b]{2}{*}{ Variables } & \multicolumn{2}{|l|}{ Model 1} & \multicolumn{2}{|l|}{ Model 2} \\
\hline & Std. Coeff. & P-value & Std. Coeff. & P-value \\
\hline \multicolumn{5}{|l|}{ Corridors } \\
\hline Bloomington & 0.022 & 0.525 & 0.013 & 0.691 \\
\hline Nicollet & 0.032 & 0.345 & 0.055 & 0.107 \\
\hline Burnsville & 0.142 & 0.000 & 0.133 & 0.000 \\
\hline Coon Rapids & 0.052 & 0.155 & 0.045 & 0.216 \\
\hline \multicolumn{5}{|l|}{ Socio-demographics } \\
\hline Age & 0.245 & 0.000 & 0.219 & 0.000 \\
\hline Number of bikes & -0.067 & 0.018 & -0.067 & 0.016 \\
\hline \multicolumn{5}{|l|}{ Transit Use } \\
\hline Commute frequency x Hiawatha ${ }^{a}$ & 0.129 & 0.000 & 0.121 & 0.001 \\
\hline Non-work frequency x Hiawatha ${ }^{a}$ & 0.061 & 0.042 & & \\
\hline Non-work frequency x Burnsville a & -0.096 & 0.000 & -0.106 & 0.000 \\
\hline Non-work frequency x Nicollet ${ }^{a}$ & & & -0.055 & 0.044 \\
\hline \multicolumn{5}{|l|}{ Neighborhood Characteristics } \\
\hline Perceived transit option & 0.138 & 0.000 & 0.117 & 0.001 \\
\hline Perceived physical-activity option & 0.124 & 0.001 & 0.139 & 0.000 \\
\hline Number of businesses within one-half mile & -0.075 & 0.018 & -0.073 & 0.019 \\
\hline \multicolumn{5}{|l|}{ Travel Preferences } \\
\hline Pro-driving & & & 0.130 & 0.000 \\
\hline Pro-travel & & & 0.162 & 0.000 \\
\hline Pro-transit x Hiawatha ${ }^{a}$ & & & 0.065 & 0.036 \\
\hline \multicolumn{5}{|l|}{ Residential Preferences } \\
\hline Transit x Hiawatha ${ }^{a}$ & & & 0.070 & 0.014 \\
\hline $\mathrm{N}$ & 1245 & & 1235 & \\
\hline Adj. R-square & 0.122 & & 0.172 & \\
\hline
\end{tabular}

${ }^{a}$ Interaction between the variable and corridor dummy.

than half are significant at the 0.01 level. Therefore, the significance of the variables is not likely to be due to chance error.

First, age and bike ownership are the only significant socio-demographic variables in Models 1 and 2. Apparently, older residents have a higher SWT, which is consistent with the literature showing that older individuals report higher levels of subjective well-being in general (Diener and Suh 1997). Bike ownership leads to a lower SWT. One explanation may be that people who own a bike and have a preference for using it may experience cycling conditions in the Twin Cities as suboptimal. Model 1 
shows that transit use is associated with SWT for some corridors. Hiawatha residents who often use transit for commute and non-work travel are more likely to have a high level of SWT than those using transit infrequently. This is likely due to the high level of service of transit in Hiawatha. By contrast, for Burnsville residents, transit use for non-work travel is a negative correlate of SWT. The automobile is the overwhelmingly dominant transportation mode in suburban neighborhoods. Using transit for nonwork travel in the suburbs implies lack of mobility options, which is inadequate to meet people's daily travel needs. Thus, the negative association is reasonable. Three neighborhood characteristics appear in Model 1: Two factors, perceived transit options and physical activity options, have positive associations, whereas business density is negatively associated with SWT. Logically, better-perceived transit options and physical activity options increase accessibility to various destinations. A better accessibility is likely linked to a higher SWT, since travel offers more options for activity participation and fulfilling basic needs (see Ettema et al. 2010). The negative effect of business density may imply that high density brings about congestion and "messy" interactions among different modes of transport and hence lowers travel satisfaction. It is worth noting that perceived accessibility is significantly correlated with SWT at the 0.05 level before the physical-activity option is incorporated into the model, and its p-value is 0.095 and about 0.3 in Models 1 and 2, respectively, and hence it is removed from the final models. After controlling for all of the variables, the Burnsville dummy is significant and positive, and there are no significant differences between Hiawatha and the other control corridors.

All but one variable significant in Model 1 are still significant in Model 2. Specifically, the interaction between non-work transit use and the Hiawatha corridor becomes insignificant. On the other hand, the interaction between non-work transit use and the Nicollet corridor enters the model with a negative sign. Taken together, this implies that transit use in areas with good transit facilities increases SWT. However, in areas with poor transit options (Burnsville, Nicollet) transit use is likely to take place if there is a lack of other transportation options, with a negative impact on SWT. Four preference variables (including interaction terms) appear in Model 2. For all corridors, individuals who favor driving and/or travel tend to have a higher SWT than others. This suggests heterogeneity between individuals in the appreciation of travel itself, which does not depend on neighborhood characteristics or travel opportunities. Altogether, however, favoring travel by any mode is associated with a higher SWT.

For the Hiawatha corridor, those who prefer transit and/or who value the importance of transit when/if they are looking for a place to live are more likely to have a high level of SWT than those who do not. That is, people who have the pro-transit attitude and/or move to the Hiawatha corridor for transit reasons profit from living near the LRT. These findings confirm that residential self-selection plays a role in how travel and neighborhood characteristics influence SWT. However, given that we tested all possible interactions, our results also imply an asymmetry in self-selection effects on SWT. Whereas the effect of good transit facilities in Hiawatha on SWT appears to be dependent on a positive predisposition toward transit, the effect of living in Burnsville seems to be independent from travel or residential preferences. The exact mechanism underlying this asymmetry, however, requires further study. One explanation may be that appreciation for good accessibility by car is more general than for good accessibility by transit. Another explanation may be that some people live in the Hiawatha corridor for reasons unrelated to travel.

Since both neighborhood characteristics and travel and residential preferences contribute to SWT, the issue of which one is more important arises. We use R-square to quantify the extents to which the explained variation in SWT is due to neighborhood characteristics and preferences, respectively (Mokhtarian and Cao 2008). To figure out the contribution of neighborhood characteristics on SWT, we first develop a FEM with neighborhood characteristics being the only independent variables (model not shown). The R-square for this model is 0.042 . This is the upper bound of their contribution. Then 
we estimate a FEM with all variables in Model 2 but neighborhood characteristics being independent variables (model not shown). The R-square for this model is 0.148 . The R-square for Model 2 is 0.183 . The difference in R-squares between the latter two models $0.035=(0.183-0.148)$ is the lower bound of the contribution of neighborhood characteristics on SWT (i.e., the net contribution after controlling for other factors). Therefore, the built environment contributes 19 percent $(=0.035 / 0.183)$ to 23 percent $(=0.042 / 0.183)$ of the explained variation in SWT. Similarly, 39 percent to 45 percent of the explained variation in SWT is due to preferences. Overall, neighborhood characteristics seem to be less important than residential self-selection in explaining SWT.

\section{Conclusions}

This study explores built environment correlates of satisfaction with travel and the role of residential selfselection in the connections using a case study of the Hiawatha LRT in the Twin Cities. First, we find evidence for self-selection effects. In particular, the significance of the interaction term between transit preference and the Hiawatha dummy in Model 2 suggests that residents living in the Hiawatha corridor do not have higher SWT than others. However, they do if they moved there because of the transit. In other words, people move to some extent into locations that allow them to have "happy travel." In addition, pro-transit people tend to profit from access to LRT, and pro-driving and pro-travel attitudes are positively associated with SWT in all corridors.

Second, neighborhood characteristics are associated with SWT after controlling for confounding factors. Specifically, business density negatively influences SWT, which makes low-density suburbs more competitive than urban areas in enhancing SWT. On the other hand, the availability of transit options and physical-activity options are positively associated with SWT, which would make urban settings more attractive in terms of SWT. This highlights the importance of transit, bike routes and sidewalks in enhancing SWT. We also find that interactions of travel and residential preferences with locational characteristics are more important than neighborhood characteristics in explaining SWT. This is contrary to the findings of most studies in the built environment and travel behavior research (Cao and Fan 2012). It appears that the effect of changes in the built environment and transportation system on travel behavior is more substantial than on SWT. This implies that using land-use and transportation policies to promote SWT may have limited effects, even if they lead to changes in travel behavior.

Finally, although the models show that living in the Hiawatha corridor does not lead to higher SWT, the Hiawatha LRT still matters. The Hiawatha corridor is positively associated with the perceived transit option factor, which in turn has a positive association with SWT (Cao 2013). In addition, combined with a transit preference or a pre-transit orientation, living in the Hiawatha corridor has an effect of SWT. Thus, the Hiawatha LRT has an indirect impact on SWT. On the other hand, about 1000 new housing units have been developed in our study area along the Hiawatha line; most (if not all) would not be available if the Hiawatha LRT had not been built. The new housing allows people who prefer transit to match their residential location and hence enjoy higher travel satisfaction.

This study has limitations that are intrinsic to the statistical control approach in a cross-sectional design. The approach assumes that preferences are antecedent to both residential choice and satisfaction with travel. However, individuals may adapt their preferences based on where they live. That is, neighborhood characteristics may influence preferences. Further, we account for the influence of transit use, which can be affected by neighborhood characteristics. Accordingly, we may understate the impacts of neighborhood characteristics on travel satisfaction in Model 2. A structural equations model may help to address these limitations. On the other hand, they are not likely to impose a critical threat to our study. First, the variables significant in Model 1 are still significant in Model 2, and their coefficients are in the same order of magnitude. Therefore, the inclusion of 
preference variables offers an incremental contribution to explaining travel satisfaction, rather than displacing neighborhood characteristics. Second, we computed lower and upper bounds of the contribution of neighborhood characteristics on travel satisfaction because of the complex relationship among variables. The upper bound captures all possible influences of neighborhood characteristics no matter whether the influences are direct or indirect (through preferences and transit use).

\section{Acknowledgments}

The data collection was funded by the Transitway Impacts Research Program in the Twin Cities. Jessica Schoner helped with survey design and administration and conducted ArcGIS analysis.

\section{References}

Abou-Zeid, M., R. Witter, M. Bierlaire, V. Kaufmann, and M. Ben-Akiva. 2012. Happiness and travel mode switching: Findings from a Swiss public experiment. Transport Policy 19(1): 93-104. doi:10.1016/j.tranpol.2011.09.009.

Babbie, E. R. 2007. The Practice of Social Research. 11th ed. Belmont, CA: Thomson Wadsworth.

Bamberg, S., and P. Schmidt. 2003. Incentives, morality, or habit? Predicting students' car use for university routes with the models of Ajzen, Schwartz, and Triandis. Environment and Behavior 35(2): 264-285. doi:10.1177/0013916502250134.

Bergstad, C., A. Gamble, T. Gärling, O. Hagman, M. Polk, D. Ettema, M. Friman, and L. Olsson. 2011. Subjective well-being related to satisfaction with daily travel. Transportation 38(1): 1-15. doi:10.1007/s11116-010-9283-z.

Bhat, C. R., and N. Eluru. 2009. A copula-based approach to accommodate residential self-selection effects in travel behavior modeling. Transportation Research Part B: Methodological 43(7): 749-765. doi:10.1016/j.trb.2009.02.001.

Bhat, C. R., and J. Y. Guo. 2007. A comprehensive analysis of built environment characteristics on household residential choice and auto ownership levels. Transportation Research Part B: Methodological 41(5): 506-526. doi:10.1016/j.trb.2005.12.005.

Boarnet, M. G., and S. Sarmiento. 1998. Can land-use policy really affect travel behavior? A study of the link between non-work travel and land-use characteristics. Urban Studies 35(7): 1155-1169. doi:10.1080/0042098984538.

Brown, B. B., and C. M. Werner. 2007. A new rail stop: Tracking moderate physical activity bouts and ridership. American Journal of Preventive Medicine 33(4): 306-309. doi:10.1016/j.amepre.2007.06.002.

Cao, J. 2013. The association between light rail transit and satisfactions with travel and life: Evidence from Twin Cities. Transportation 40(5): 921-933. doi:10.1007/s11116-013-9455-8.

Cao, X., and Y. Fan. 2012. Exploring the influences of density on travel behavior using propensity score matching. Environment and Planning B: Planning and Design 39(5): 459-470. doi:10.1068/b36168.

Cao, X., P. L. Mokhtarian, and S. L. Handy. 2009. Examining the impacts of residential self-selection on travel behavior: A focus on empirical findings. Transport Reviews 29(3): 359-395. doi:10.1080/01441640802539195. 
Chatman, D. G. 2009. Residential choice, the built environment, and nonwork travel: evidence using new data and methods. Environment and Planning A 41: 1072-1089. doi:10.1068/a4114.

Deci, E. L., and R. M. Ryan. 2000. The "what" and "why" of goal pursuits: Human needs and the self-determination of behavior. Psychological Inquiry 11(4): 227-268. doi:10.1207/S15327965PLI1104_01.

Delbosc, A., and G. Currie. 2011. Exploring the relative influences of transport disadvantage and social exclusion on well-being. Transport Policy 18(4): 555-562. doi:10.1016/j.tranpol.2011.01.011.

Diener, E., E. M. Suh, R. E. Lucas, and H. L. Smith. 1999. Subjective well-being: Three decades of progress. Psychological Bulletin 125: 276-302. doi:10.1037/0033-2909.125.2.276.

Diener, E., and E. Suh. 1997. Measuring quality of life: Economic, social, and subjective indicators. Social Indicators Research 40(1-2): 189-216. doi:10.1023/A:1006859511756.

Ettema, D., M. Friman, T. Gärling, L. E. Olsson, and S. Fujii. 2012. How in-vehicle activities affect work commuters' satisfaction with public transport. Journal of Transport Geography 24(0): 215-222. doi:10.1016/j.jtrangeo.2012.02.007.

Ettema, D., T. Gärling, L. E. Olsson, and M. Friman. 2010. Out-of-home activities, daily travel, and subjective well-being. Transportation Research Part A: Policy and Practice 44 (9): 723-732. doi:10.1016/j. tra.2010.07.005.

Frank, L. D., B. E. Saelens, K. E. Powell, and J. E. Chapman. 2007. Stepping towards causation: Do built environments or neighborhood and travel preferences explain physical activity, driving, and obesity? Social Science \& Medicine 65(9): 1898-1914. doi:10.1016/j.socscimed.2007.05.053.

Friman, M. , and M. Felleson. 2009. Service supply and customer satisfaction in public transportation: The quality paradox. Journal of Public Transportation 12(4): 57-69.

Friman, M., and T. Gärling. 2001. Frequency of negative critical incidents and satisfaction with public transport services. II. Journal of Retailing and Consumer Services 8(2): 105-114. doi:10.1016/S09696989(00)00003-5.

Hennessy, D. A., and D. L. Wiesenthal. 1999. Traffic congestion, driver stress, and driver aggression. Aggressive Behavior 25: 409-423. doi:10.1002/(SICI)1098-2337(1999)25:6\%3C409::AIDAB2\%3E3.0.CO;2-0.

Huta, V., and R. M. Ryan. 2010. Pursuing pleasure or virtue: The differential and overlapping wellbeing benefits of hedonic and eudaimonic motives. Journal of Happiness Studies 11(6): 735-762. doi:10.1007/s10902-009-9171-4.

Jain, J., and G. Lyons. 2008. The gift of travel time. Journal of Transport Geography 16(2): 81-89. doi:10.1016/j.jtrangeo.2007.05.001.

Khattak, A. J., and D. Rodriguez. 2005. Travel behavior in neo-traditional neighborhood developments: A case study in USA. Transportation Research Part A-Policy and Practice 39(6): 481-500. doi:10.1016/j.tra.2005.02.009.

Krizek, K. J. 2003. Residential relocation and changes in urban travel: Does neighborhoodscale urban form matter? Journal of the American Planning Association 69(3): 265-281. doi:10.1080/01944360308978019.

Middleton, J. 2009. Stepping in time: walking, time, and space in the city. Environment and Planning A 41(8): 1943-1961. doi:10.1068/a41170.

Mokhtarian, P. L., and X. Cao. 2008. Examining the impacts of residential self-selection on travel behavior: A focus on methodologies. Transportation Research Part B: Methodological 42 (3): 204-228. doi:10.1016/j.trb.2007.07.006.

Mokhtarian, P. L., and I. Salomon. 2001. How derived is the demand for travel? Some conceptual and measurement considerations. Transportation Research Part A: Policy and Practice 35(8): 695-719. 
doi:10.1016/S0965-8564(00)00013-6.

Næss, P. 2009. Residential self-selection and appropriate control variables in land use: Travel studies. Transport Reviews 29(3): 293-324. doi:10.1080/01441640802710812.

Olsson, L. E., T. Gärling, D. Ettema, M. Friman, and S. Fujii. 2013. Happiness and satisfaction with work commute. Social Indicators Research 111(1): 255-263. doi:10.1007/s11205-012-0003-2.

Pinjari, A. R., R. M. Pendyala, C. R. Bhat, and P. A. Waddell. 2011. Modeling the choice continuum: An integrated model of residential location, auto ownership, bicycle ownership, and commute tour mode choice decisions. Transportation 38(6): 933־-958. doi:10.1007/s11116-011-9360-y.

Ryff, C. D., and B. H. Singer. 2008. Know thyself and become what you are: A eudaimonic approach to psychological well-being. Journal of Happiness Studies 9(1): 13-39. doi:10.1007/s10902-006-90190 .

Scheiner, J. 2010. Social inequalities in travel behavior: Trip distances in the context of residential self-selection and lifestyles. Journal of Transport Geography 18(6): 679-690. doi:10.1016/j.jtrangeo.2009.09.002.

Snijders, T., and R. Bosker. 1999. Multilevel Analysis: An Introduction to Basic and Advanced Multilevel Modeling. London, UK: Sage Publications.

Sommer, B. B., and R. Sommer. 1997. A Practical Guide to Behavioral Research: Tools and Techniques. 4th ed. New York: Oxford University Press.

Stanbridge, K., and G. Lyons. 2006. Travel behavior considerations during the process of residential relocation. Paper read at 11th International Conference on Travel Behavior Research, Kyoto, Japan.

Stanley, J. K., D. A. Hensher, J. R. Stanley, and D. Vella-Brodrick. 2011. Mobility, social exclusion and well-being: Exploring the links. Transportation Research Part A: Policy and Practice 45 (8): 789-801. doi:10.1016/j.tra.2011.06.007.

Stutzer, A., and B. S. Frey. 2008. Stress that does not pay: The commuting paradox. Scandinavian Journal of Economics 110: 339-366. doi:10.1111/j.1467-9442.2008.00542.x.

Zhou, Bin, and Kara Kockelman. 2008. Self-selection in home choice: Use of treatment effects in evaluating relationship between built environment and travel behavior. Transportation Research Record: Journal of the Transportation Research Board 2077: 54-61. doi:10.3141/2077-08. 